\title{
Quality of Life after Accidental Major Vascular Injury and Prolonged ICU Stay - A Case Report
}

\author{
Mitra $\mathrm{S}^{* 1}$, Supriya $\mathrm{M}^{2}$, Subhabrata $\mathrm{N}^{3}$, Asima $\mathrm{M}^{4}$ and Goswami $\mathrm{J}^{1}$ \\ ${ }^{1}$ Department of Anesthesiology and Critical Care and Pain, Tata Medical Center, Kolkata, India \\ ${ }^{2}$ Nursing Gynaecology Oncology, Clinical Nurse Specialist, Kolkata, India \\ ${ }^{3}$ Critical Care, Tata Medical Center, Kolkata, India \\ ${ }^{4}$ Gynaecological Oncology, Tata Medical Center, Kolkata, India
}

*Corresponding author: Mitra S, Department of Anesthesiology and Critical Care and Pain, Tata Medical Center, Kolkata, India, Tel: +91-8017552743, E-mail: suparna.mitrabarman@gmail.com; suparna.barman@tmkolkata.com

Citation: Mitra S, Supriya M, Subhabrata N, Asima M, Goswami J (2018) Quality of Life after Accidental Major Vascular Injury and Prolonged ICU Stay - A Case Report. J Case Rep Stud 6(3): 305.

doi: 10.15744/2348-9820.6.305

Received Date: May 15, 2018 Accepted Date: June 25, 2018 Published Date: June 27, 2018

\begin{abstract}
Survival or mortality rate is a reasonable choice of an outcome measure for critically ill patients in intensive care unit (ICU). But it is also important to assess the impact of critical illness and peri-operative complications on health status and quality of life (QoL) after hospital discharge. The QLQ-C30 is a 30-item cancer-specific questionnaire that incorporates five functioning scales (physical, role, cognitive, emotional, and social), eight symptoms scales, perceived financial impact of the disease and a global scale [1-5]. This questionnaire indicates a patient's capacity to achieve the activities of daily living [2-4,6]. In this article, we discussed QoL of an ovarian cancer patient, who had intra-operative major vascular injury followed by prolonged ICU stay.
\end{abstract}

Keywords: QoL; ICU; Cancer; Questionnaire

List of abbreviations: ICU: Intensive Care Unit; QoL: Quality of Life; IVC: Inferior Vena Cava; POD: Postoperative Day; PRBC: Packed Red Blood Cells; FFP: Fresh Frozen Plasma; EORTC: European Organisation for Research and Treatment of Cancer

\section{Introduction}

A 38 years old female, with carcinoma ovary was scheduled for Interval de-bulking surgery, following chemotherapy. Preanaesthesia evaluation, induction, and maintenance of anaesthesia were uneventful. Initial 8 hours, of en-block removal of specimen with total omentectomy was uneventful. Due to the chemotherapy effect, there was an extensive fibrosis with scarring in the right diaphragm. In order to achieve complete cytoreduction, there was laceration of the right hepatic vein during right diaphragmatic stripping. This resulted in sudden gush of massive blood loss of $1000 \mathrm{ml}$ within 10 minutes and hypotensive shock. She was revived with fluid resuscitation, vasopressors and ionotrops. Meanwhile, the surgical team was able to control bleeding by ligating the injured vein after clamping of the inferior vena cava (IVC) for 32 minutes. Total blood loss was four litres and she received the transfusion of seven unit PRBC and three units of FFP. In the ICU, haemodynamic support was continued till fifth postoperative day (POD). Due to high temperature, antimicrobial agents and anti-fungal agents (carbapenem, colistin, teicoplanin, and fluconazole) were started empirically on the 1st POD. Ventilator support was continued as weaning trial failed even on the tenth day, which led to tracheostomy. On 14th POD she had significant endotracheal bleeding leading to near-arrest situation, from which she was revived and put back to lung-protective ventilator support. Her condition started improving slowly after bronchoscopy with suction and lavage on the 16th POD. Active weaning was started on the 22nd POD, which she tolerated well. Tracheostomy tube was removed on 28th POD and she was discharged on 31st POD.

Being a young mother,with domestic and social responsibilities, we planned to assess her quality of life (QoL) after discharge to find out the impact of the disease, treatment, surgery and prolonged ICU stay on her physical, psychological and functional state. In our Institution, for all ovarian cancer patients under follow-up period after surgery, in 6 weeks, 3 months and 6 months, for QoL, a trained clinical nurse specialist in gynaecological oncology, routinely collects relevant data by face-to-face or telephonic interview with the use of EORTC tools (QLQ- C 30 and Ov-28 translated in local language) (Table 1 and 2).

There was significant improvement noted in some of the physical activities as follows: need to stay in bed or a chair during the day, need to take rest, trouble in sleeping or doing short work, need help with eating/dressing/washing, and improvement in physical symptoms including pain, weakness, decreased appetite, feeling tired, nausea, vomiting, diarrhoea etc. Changes were noticed in some of the cognitive and emotional functions also, which include feeling tense, difficulty remembering things etc. and 
interference with social activities. There was gradual improvement in the scores i.e. 4 (very much) at 6 weeks, 3 (moderate) at 3 months to 1 (almost nil) at 6 months follow-up period (Table 1 and 2).

\begin{tabular}{|c|c|c|c|c|}
\hline Q.NO & Statement & 6 Weeks & 3 Months & 6 Months \\
\hline 1 & Do you have any trouble doing strenuous activities, like carrying a heavy shopping bag or a suitcase? & NA & NA & 1 \\
\hline 2 & Do you have any trouble taking a long walk? & NA & 4 & 3 \\
\hline 3 & Do you have any trouble taking a short work outside of the house? & 3 & 2 & 1 \\
\hline 4 & Do you need to stay in bed or a chair during the day? & 4 & 3 & 1 \\
\hline 5 & Do you need help with eating, dressing, washing yourself or using the toilet? & 3 & 1 & 1 \\
\hline 6 & Were you limited in doing either your work or other daily activities? & NA & 3 & 1 \\
\hline 7 & Were you limited in pursuing your hobbies or other leisure time activities? & NA & 2 & 1 \\
\hline 8 & Were you short of breath? & 3 & 2 & 2 \\
\hline 9 & Have you had pain? & 3 & 1 & 1 \\
\hline 10 & Did you need to rest? & 4 & 3 & 1 \\
\hline 11 & Have you had trouble sleeping? & 4 & 3 & 1 \\
\hline 12 & Have you felt week? & 3 & 3 & 1 \\
\hline 13 & Have you lacked appetite? & 3 & 3 & 1 \\
\hline 14 & Have you felt nauseated? & 2 & 1 & 1 \\
\hline 15 & Have you vomited? & 2 & 1 & 1 \\
\hline 16 & Have you been constipated? & 3 & 3 & 2 \\
\hline 17 & Have to have diarrhoea? & 1 & 2 & 1 \\
\hline 18 & Were you tired? & 3 & 3 & 1 \\
\hline 19 & Did pain interfere with your daily activities? & NA & 1 & 1 \\
\hline 20 & Have you had difficulty in concentrating on things, like reading a newspaper or watching television? & NA & 2 & 1 \\
\hline 21 & Did you feel tense? & 2 & 1 & 1 \\
\hline 22 & Did you worry? & 2 & 3 & 2 \\
\hline 23 & Did you feel irritable? & 2 & 3 & 2 \\
\hline 24 & Did you feel depressed? & 3 & 3 & 2 \\
\hline 25 & Have you had difficulty remembering things? & 3 & 1 & 1 \\
\hline 26 & Has your physical condition or medical treatment interfered with your family life? & 4 & 2 & 1 \\
\hline 27 & Has your physical condition or medical treatment interfered with your social activities? & 4 & 2 & 1 \\
\hline 28 & Has your physical condition or medical treatment caused you financial difficulties? & 4 & 4 & 4 \\
\hline 29 & How do you rate your overall health during the past week? & 3 & 4 & 6 \\
\hline 30 & How do you rate your overall quality of life during the past week? & 3 & 4 & 6 \\
\hline
\end{tabular}

\section{Table 1: Quality of Life}

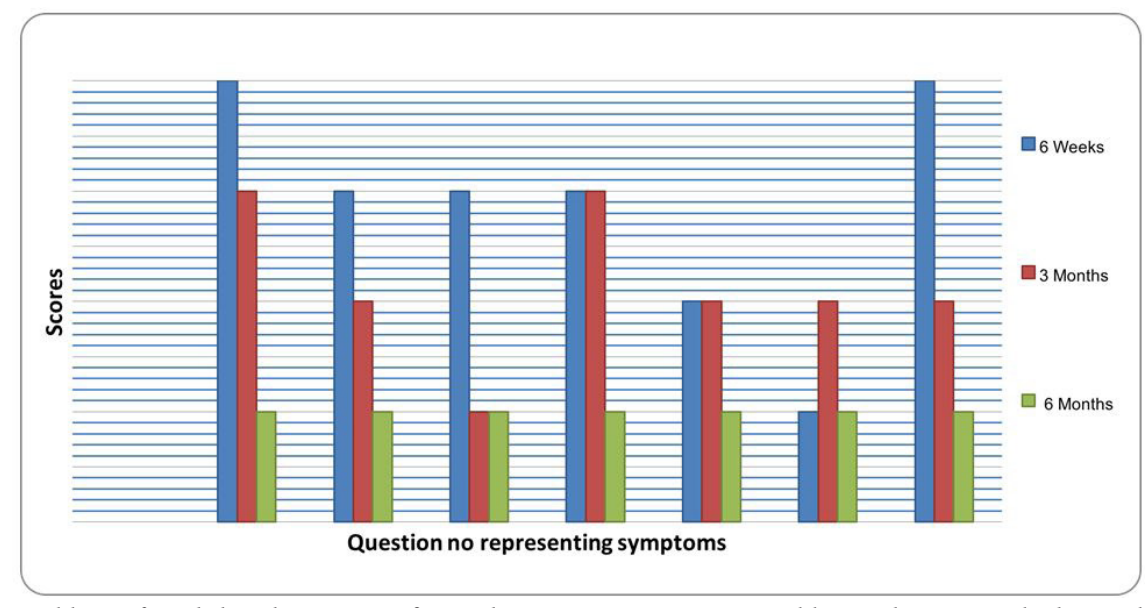

From the above table we found that there is significant changes in some symptoms like need to stay in bed or a chair during the day, need to take rest, trouble sleeping, trouble in doing short work, need help with eating, dressing, washing, having pain, difficulty remembering things, weakness, decreased appetite, feeling tired, nausea, vomiting, feeling tense, diarrhoea, difficulty in remembering things, treatment interfered with your social activities etc. Changes occur during 6 weeks, 3 months and 6 months follow-up period. All these symptom's scores ranges from 4 and 3 to 1 i.e from very much and moderate to not at all in 6 months follow-up. Table 2: Question no representing systems 


\section{Discussion}

Patients with ovarian cancer undergoing surgery are highly distressed group. Younger, educated and newly diagnosed subgroup was found to be more susceptible. Their problems have different dimension, as they have to come up with this new diagnosis of cancer affecting their mental and physical health, relation with family, social and job responsibility etc [7,8]. After the surgery, this distress increases as they have to adjust with the disruption to the own and family life, the loss of reproductive function affecting their sense of self-worth and feminine identity, the effects of premature menopause leading to sexual dysfunction, physical discomfort, and the mood derangement [9]. Early screening is advocated to recognise the symptoms early and to provide a baseline to which future symptoms may be compared [10]. Our patient coped up well as she had undergone regular counselling by a specially trained nurse during her ICU stay $[4,5,11]$. Major distress at discharge improved slowly to almost normal status after 6 months.

\section{Conclusion}

Postoperative ovarian cancer patients with prolong ICU stay, because of undue complications, are vulnerable group to have lower QoL after discharge.Regular psychological counselling should be incorporated in routine ICU care, which prepares them to cope up with the stressful situation better. It is also important to measure QoL in such patients to understand how peri-operative care can affect the psychological, physical, and social well-being of the survivors.

\section{References}

1.Oeyen SG, Vandijck DM, Benoit DD, Annemans L, Decruyenaere JM (2010) Quality of life after intensive care: A systematic review of the literature. Crit Care Med 38: 2386-400.

2. Fayers PM, Aaronson NK, Bjordal K(1995) EORTC QLQ- C30 Scoring Manual. Brussels: EORTC Study Group on Quality of Life.

3. Hubert RJ, Dassen T, Widdershoven G, Halfens R (2009) Reliability and validity of the EORTC OLO-C30 in palliative care cancer patients. Cent Eur J Med 4: 348-57.

4. Velikova G, Coens C, Efficace F, Greimel E, Groenvold M, et al. (2012) Health related quality of life in EORTC clinical trials-30 years of progress from methodological developments to making real impact on oncology practice. EJC Suppl 10: 141-9.

5. Agarwal S,Bodurka DC (2010) Symptom research in gynecologic oncology: a review of available measurement tools .Gynecol Oncol 119: 384-9.

6. Aaronson NK, Ahmedzai S, Bergman B (1993) The European Organisation for Research and Treatment of cancer QLQ-C30: a quality -of -life instrument for use in internetonal clinical trials in oncology. J Natl Cancer Inst 85: 365-76.

7. Charlotte C, Pedro T, Diane C (2007) Quality of life for patients with epithelial ovarian cancer. Nat Clin Pract Oncol 4: 18-29.

8. Friedlander ML, King MT (2013) Patient-reported outcomes in ovaryan cancer clinical trials. Ann Oncol 24: 64-8.

9. Schulman-green D, Ercolano E, Dowd M, Schwartz P, Mccorkle R (2008) Quality of life among women after surgery for ovarian cancer. Palliat Support Care 6: 239-47.

10. McCorkle R, Pasacreta J, Tang ST (2003) The silent killer: Psychological issues in ovarian cancer. Holist Nurs Pract 17: 300-8.

11. Hegel MT, Moore CP, Collins ED, Kearing S, Gillock KL, et al. (2006) Distress, psychiatric syndromes and impairment of function in women with newly diagnosed breast cancer. Cancer 107: 2924-31.

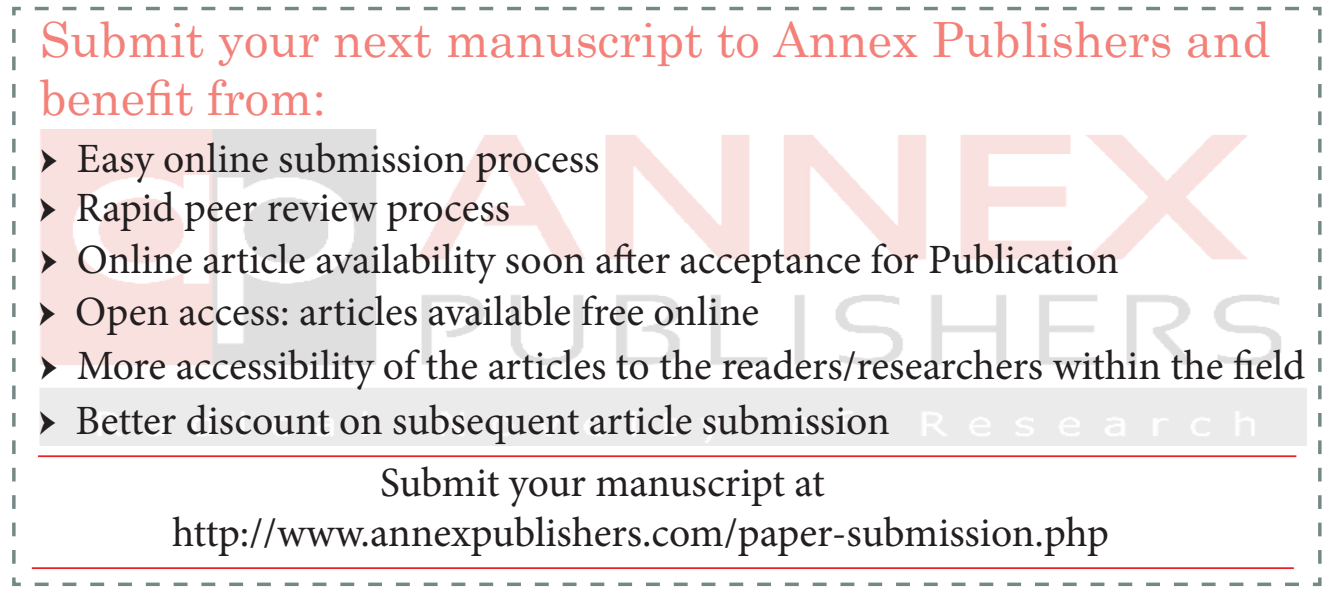

